Conclusion: The BMD in the region of total hip, femoral neck, ultra-distal radius, and total body in patients with decreased muscle mass was significantly lower than in patients without low lean mass.

REFERENCES:

[1] Cruz-Jentoft AJ, Bahat G, Bauer J, et al. Sarcopenia: revised European consensus on definition and diagnosis [published correction appears in Age Ageing. 2019 Jul 1;48(4):601]. Age Ageing. 2019;48(1):16-31

Disclosure of Interests: None declared

DOI: 10.1136/annrheumdis-2021-eular.3641

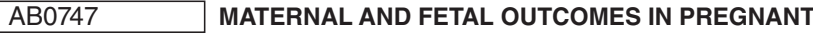 WOMEN WITH JUVENILE IDIOPATHIC ARTHRITIS: A SYSTEMATIC LITERATURE REVIEW}

R. Pinheiro Torres ${ }^{1,2}$, M. H. Fernandes Lourenco ${ }^{1,2}$, A. Neto ${ }^{1,2,3}$, F. Pimentel Dos Santos $^{1,2,4}$, I. Silva ${ }^{1,4}$, A. F. Mourão ${ }^{1,2,4}$, H. Donato ${ }^{5}$, M. Costa ${ }^{1}$,

J. Branco $1,2,4$. ${ }^{1}$ Hospital Egas Moniz, Rheumatology, Lisboa, Portugal; ${ }^{2}$ CEDOC, Rheumatology, Lisboa, Portugal; ${ }^{3}$ Hospital Central Funchal, Rheumatology, Funchal, Portugal; ${ }^{4}$ Nova Medical School, Rheumatology, Lisboa, Portugal; ${ }^{5}$ Centro Hospitalar e Universitário de Coimbra, 5. Serviço de Documentação e Informação Científica, Coimbra, Portugal

Background: Juvenile idiopathic arthritis (JIA), one of the most common chronic diseases in children, can be classified in seven different categories according to its onset presentation. Concerns about pregnancy outcomes play a secondary role in disease approach. However, recent data showed an increased risk of preterm birth in women with JIA instead the small patient samples analysed.

Objectives: In this review, our aim is to describe the current available knowledge on JIA adverse, maternal and fetal, outcomes.

Methods: A systematic literature review was conducted since January of 2000 until December 2020, by searching the PubMed and Embase bibliographic databases. The search was limited to articles in English language, presenting a comparator group (healthy individuals or patients without known auto-immune rheumatic diseases) and at least one clinical outcome of interest. Two independent reviewers screened the titles and abstracts followed by a full-text review to assess papers regarding their eligibility.

Results: Ten observational studies out of 1560 references, fulfilled the inclusion criteria, of which, 9 were retrospective and 1 prospective. A total of 6.214 women with JIA (with 6.811 pregnancies) and 18.659 .513 healthy controls (with 21.339.194 pregnancies) were included in this review.

Concerning maternal outcomes, delivery by caesarian section (CS) was more frequent among JIA women (in 4 out of 6 studies). Pre-eclampsia was referred in 3 out of 6 studies and a higher risk of vaginal bleeding and placenta previa in one additional study. No study found an increased risk for gestational diabetes or hypertension in pregnant women with JIA.

Regarding fetal outcomes, 8 studies revealed significantly increased of pre-term birth (only in first births in one study) but one study didn't show any increased risk. Two studies showed a higher risk of small gestational age (SGA) and in another 2, increased risk for low birth weight (LBW). No evidence of increased risk of major congenital malformations.

Conclusion: This systematic review suggests an increased risk for pre-eclampsia, preterm birth, delivery by CS, SGA and LBW, among pregnant women with JIA. Conclusions should be carefully interpreted, giving the heterogeneity of studied populations regarding demography, disease type, disease activity, and prescribed medication.

Disclosure of Interests: None declared

DOI: 10.1136/annrheumdis-2021-eular.3647

\section{AB0748 ARE ANY DIFFERENCES BETWEEN JIA - ASSOCIATED UVEITIS, DEVELOPED BEFORE AND AFTER JOINT MANIFESTATION}

M. Chakhalian ${ }^{1}$, E. Gaidar ${ }^{2}$, T. Nikitina ${ }^{3}$, E. Isupova ${ }^{4}$, I. Chikova ${ }^{2}$, M. Dubko ${ }^{2}$ V. Masalova ${ }^{2}$, T. Likhacheva ${ }^{2}$, L. Snegireva ${ }^{2}$, M. Kaneva ${ }^{2}$, O. Kalashnikova ${ }^{2}$, V. Chasnyk ${ }^{2}$, M. Kostik ${ }^{2}$. 'Saint-Petersburg State Pediatric Medical University, Department of Hospital Pediatrics, Pediatric Rheumatology (Department of Pediatrics \#3); Hospital Pediatry, Saint-Petersburg, Russian Federation; ${ }^{2}$ Saint-Petersburg State Pediatric Medical University, SaintPetersburg State Pediatric Medical University; Pediatric Rheumatology, Saint-Petersburg, Russian Federation; ${ }^{3}$ Saint-Petersburg State Pediatric Medical University, Saint-Petersburg State Pediatric Medical University; Ophthalmologist, Hospital Pediatry, Saint-Petersburg, Russian Federation ${ }^{4}$ Saint-Petersburg State Pediatric Medical University, Department of Hospital Pediatrics, Pediatric Rheumatology, Saint-Petersburg, Russian Federation
Background: Uveitis is the most common extra-articular manifestation of juvenile idiopathic arthritis (JIA). Usually uveitis developed during first two years after arthritis occurred [1]. In the previous studies was shown the shorter time interval between arthritis and uveitis the severe uveitis course was observed [2]. Information about course of uveitis developed before arthritis is scarce. Objectives: We aimed to evaluate the clinical features and therapy of JIA-associated uveitis, which developed before and after joint manifestation.

Methods: In the retrospective study 191 pediatric autoimmune uveitis included The onset age ranged from 1 to 17 years. We evaluated differences in clinical laboratorial and treatment differences between groups, i) where uveitis developed before $(n=58)$ and ii) after $(n=133)$ arthritis. Chronic autoimmune uveitis without joint manifestations was excluded.

Results: Uveitits before arthritis developed in 58 (30.4\%) cases. Patients whom uveitis developed before arthritis had were elder and characterized equal gender involvement, rare ANA positivity, and rare use of immunosupression, e.g corticosteroids, biologics and methotrexate, due to treatment by ophthalmologis predominantly. Patients developed uveitis before arthritis received biologics earlier due to severity of uveitis (LogRank test, $\mathrm{p}=0.016, \mathrm{HR}=1.97(95 \% \mathrm{Cl}$ : 1.3; 3.1 $\mathrm{p}=0.004)$. Data are in the Table 1 and Figure 1.

Conclusion: Patients with JIA associated uveitis with initial ocular presentation demonstrated more severe course and delayed diagnostics and treatment due to lack of contacts with pediatric rheumatologist. Cooperation between ophthalmologist and pediatric rheumatologist is strictly required in all cases with chronic anterior uveitis.

Table 1.

\begin{tabular}{|c|c|c|c|}
\hline Parameter & $\begin{array}{l}\text { Uveitis before arthritis } \\
\qquad(\mathrm{n}=58)\end{array}$ & $\begin{array}{l}\text { Uveitis after arthritis } \\
\qquad(n=133)\end{array}$ & $\mathrm{p}$ \\
\hline Sex, female & $32(55,2)$ & $97(72,9)$ & 0.016 \\
\hline $\begin{array}{l}\text { Onset age, years } \\
\text { JIA category }\end{array}$ & $6.7(4.6 ; 10.2)$ & $3.2(2 ; 6.1)$ & 0.000001 \\
\hline Oligoarthritis & $41(70.7)$ & $84(63.6)$ & 0.174 \\
\hline Polyarthritis & $9(15.5)$ & $36(27.3)$ & \\
\hline Enthesytis-related arthritis & $8(13.8)$ & $12(9.1)$ & \\
\hline Type of uveitis & & & \\
\hline Anterior & 44 (75.9) & $111(84.1)$ & 0.315 \\
\hline Peripheral & $3(5.2)$ & $2(1.5)$ & \\
\hline Posterior & $3(5.2)$ & $3(2.3)$ & \\
\hline Panuveitis & $8(13.8)$ & $16(12.1)$ & \\
\hline Unilateral uveitis, n (\%) & $19(32.8)$ & $48(36.1)$ & 0.632 \\
\hline ANA posititivity, n (\%) & $25 / 54(46.3)$ & $72 / 110(65.5)$ & 0.019 \\
\hline HLA B27 positivity, n (\%) & $8 / 35(22.9)$ & $13 / 62(21.0)$ & 0.828 \\
\hline Methotrexate, n (\%) & $3(5.2)$ & $57 / 132(43.2)$ & 0.0000001 \\
\hline Systemic corticosteroids, n (\%) & $3(5.2)$ & $44 / 131(33.6)$ & 0.00003 \\
\hline Biologic, n (\%) & $26(44.8)$ & $88(66.2)$ & 0.006 \\
\hline $\mathrm{ESR}, \mathrm{mm} / \mathrm{h}$ & $19.0(4.0 ; 25.0)$ & $23(15.0 ; 32.0)$ & 0.095 \\
\hline CRP, mg/l & $97.0(0.1 ; 107.5)$ & $8.1(0.9 ; 57.4)$ & 0.493 \\
\hline $\begin{array}{l}\text { Time between arthritis and uveitis, } \\
\text { years }\end{array}$ & $2.7(0.9 ; 4.3)$ & $4.0(2.0 ; 7.1)$ & 0.016 \\
\hline Time before biologic, years & $2.5(0.9 ; 3.5)$ & $1.3(0.5 ; 5.0)$ & 0.462 \\
\hline
\end{tabular}

This work supported by the Russian Foundation for Basic Research (grant № 18-515-57001).

\section{REFERENCES:}

[1] Verazza S, et al. Pediatr Rheumatol Online J 2008;6(Suppl 1):77.

[2] Zannin ME, et al. Acta Ophthalmol 2012;90:91-5.

Disclosure of Interests: None declared

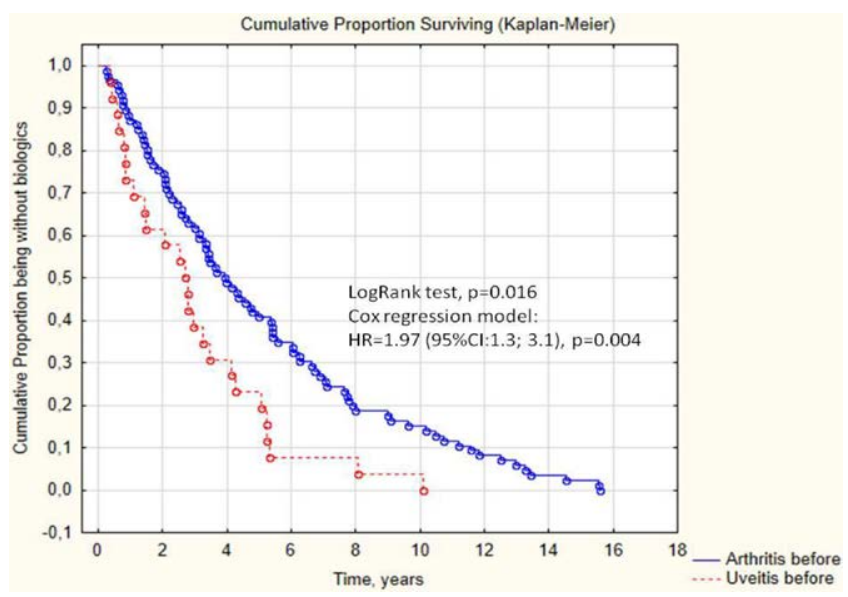

Figure 1.

DOI: 10.1136/annrheumdis-2021-eular.3704 